\title{
A narrativa oral, a análise de discurso e os estudos de gênero
}

\author{
Maria Lúcia Rocha-Coutinho \\ Universidade Federal do Rio de Janeiro
}

\begin{abstract}
Resumo
Neste trabalho desenvolvemos a idéia de que os Estudos de Gênero inserem-se na nova tradição em ciência, que alguns autores denominam pós-empírica, que questiona a objetividade do conhecimento e a impessoalidade do pesquisador e que toma como importante a dimensão interpretativa da realidade social. Dentro dessa tradição, acreditamos que o uso da narrativa oral e da análise de discurso pode ser um rico e poderoso instrumento para uma melhor compreensão de mulheres e homens e, assim, em muito pode contribuir para os Estudos de Gênero nas Ciências Humanas e Sociais, em geral, e na Psicologia, em particular.
\end{abstract}

Palavras-chave: narrativa oral; análise de discurso; estudos de gênero

\begin{abstract}
Oral narrative, discourse analysis and gender studies. In this work we argue that Gender Studies can be seen as part of the new tradition in science, that some authors call post-empirical, which questions the objectivity of knowledge and the impersonality of researchers and which takes the interpretative dimension of social reality as important. In accordance with this tradition, we believe that the use of oral narrative and of discourse analysis can be a rich and powerful instrument to a better understanding of women and men and, thus, can greatly contribute to Gender Studies in Social Sciences, in general, and in Psychology, in particular.

Keywords: oral narrative; discourse analysis; gender studies
\end{abstract}

\section{Estudos de Gênero e metodologia científica ${ }^{1}$}

$\mathrm{S}$ egundo Nielsen (1990), assim como os estudos feministas alteraram as disciplinas acadêmicas - da crítica literária à história, às ciências sociais e humanas -, as pesquisas feministas vêm também contribuindo para uma verdadeira transformação nas metodologias tradicionalmente empregadas nos estudos acadêmicos.

$\mathrm{Na}$ área dos estudos de gênero, a abertura a um leque de metodologias alternativas - freqüentemente qualitativas, como é o caso, por exemplo, do amplo emprego da narrativa oral, de que vamos falar adiante - àquelas empregadas nos meios acadêmicos tradicionais se deu, em grande parte, em resposta à insatisfação com os métodos usualmente empregados para dar conta de questões ligadas às mulheres, bem como em decorrência de um esforço significativo para ampliar os temas abrangidos por suas investigações e os novos enfoques que se descortinavam.

Estas metodologias, contudo, quando comparadas às metodologias tradicionais no âmbito das ciências naturais, pareceram, a princípio, especialmente para alguns pesquisadores com formação nestas últimas perspectivas, pouco "científicas” e frágeis, tendo sido alvo de críticas que, em muitos momentos, parecem fruto de um exercício, a meu ver, bastante autoritário de intolerância. Exemplo disso foram as du- ras críticas sofridas por Robin Lakoff à metodologia - ou à suposta ausência de, para alguns - empregada pela autora em seu estudo pioneiro Language and Woman's Place ${ }^{2}$.

Em grande parte, esse tipo de crítica é decorrência da dicotomia pouco fértil que opõe metodologias quantitativas a qualitativas ${ }^{3}$, em que os estudiosos que se dedicam às primeiras freqüentemente desqualificam as segundas, pretendendo reger sozinhos o destino de toda investigação científica. Grande parte das críticas a essas novas metodologias centra-se na idéia de que elas seriam pouco científicas por se afastarem do que Bruner (1997) denomina uma epistemologia verificacionista, baseando-se na interpretação. Segundo este autor, a validade - aspecto importante nas metodologias quantitativas - é também um conceito interpretativo. Para ele, o fundamental é a plausibilidade da conclusão e esta pode estar presente no uso de metodologias quantitativas e/ou qualitativas. $^{4}$

\section{Modernidade e método científico}

Uma das principais características da modernidade foi a autoridade inquestionável do método científico como a melhor forma para se estudar tanto os fenômenos naturais quanto os sócio-culturais. Nesta tradição científica, podemos distinguir duas tendências dominantes, o racionalismo e o empirismo. Não vou me deter nesta questão, mas apenas 
mencionar alguns pontos que considero importantes para o desenvolvimento do meu raciocínio.

No racionalismo, o modo mais antigo, há um domínio da razão pura, ou lógica, que se impõe, fazendo com que desapareça o interesse pela observação. A famosa frase de Descartes, “penso, logo existo”, é considerada verdadeira exatamente porque haveria uma contradição entre pensar e não existir, isto é, a primeira parte da afirmação torna a negação da segunda ilógica, fazendo com que qualquer tipo de observação seja desnecessária. O empirismo, ao contrário, é o processo de observação direta, de registro e/ou monitoração dos mundos natural e/ou social. As tendências dominantes no pensamento ocidental abrangem uma combinação de racionalismo (que agora assume a forma de lógica) e empirismo na ciência moderna.

A despeito das mudanças nas epistemologias dominantes, uma questão que tem caracterizado o discurso ocidental sobre o conhecimento é a da oposição objetivismo versus relativismo. Desde Platão, há uma tendência em se assumir uma ou outra posição acerca da possibilidade de se obter um conhecimento absoluto e inquestionável sobre o mundo. Em um extremo encontram-se aqueles filósofos que passaram grande parte de suas vidas buscando uma base ou fundamento para se chegar ao conhecimento absoluto, presumindo que existe um mundo objetivo a ser conhecido, isto é, independente do sujeito do conhecimento.

No outro extremo estão aqueles que acreditam que não há uma verdade última, final, objetiva, com a qual todos concordem. A versão moderna deste cepticismo é o relativismo, que afirma que todo conhecimento está ligado a uma cultura, a uma teoria e, assim, é histórico por natureza. Deste modo, ele só pode ser compreendido e considerado válido para uma teoria ou perspectiva específicas e em um tempo e lugar determinados.

De modo geral, o método científico pode ser definido como aquele que inclui uma evidência empírica, experimentação (isto é, a manipulação proposital de um dado ou de eventos a fim de se aferir seus efeitos), e o uso de uma lógica indutiva - inferência de uma afirmação mais geral a partir de um acontecimento particular, geralmente uma observação ou dedutiva - inferência que segue necessariamente de uma premissa a uma conclusão.

Durante seus anos de formação, as ciências humanas e sociais, em sua busca por respeitabilidade acadêmica, usaram a física e seus métodos como modelo. Assim, elas partiram do princípio de que o mundo social poderia ser explorado e estudado do mesmo modo que o mundo físico, daí decorrendo uma série de premissas. Entre elas podemos mencionar a crença no fato de que o mundo social é passível de conhecimento do mesmo modo que o mundo natural, através da observação e do registro de fatos objetivos por um sujeito do conhecimento neutro, isto é, que está apartado do objeto a ser conhecido. Assim, pressupõe-se que diferentes observadores expostos aos mesmos dados chegarão a conclusões semelhantes ${ }^{5}$.

Além disso, acredita-se que o mundo social, como o mundo físico, é ordenado e racional e este padrão toma pre- dominantemente a forma causa-efeito. Deste modo, a despeito das variações históricas e culturais, presume-se a existência de algo permanente e regular sobre a vida social, que pode ser apreendida a partir de leis gerais e abstratas. Finalmente, podemos dizer que se parte do pressuposto de que há uma unidade entre as ciências no que diz respeito à metodologia empregada para apreender o mundo, seja ele físico ou social, e de que esta metodologia é o melhor, senão o único, meio legítimo em que o conhecimento deve estar assentado. As conclusões científicas são sempre provisórias, isto é, abertas a modificações subseqüentes, mas as regras e os procedimentos da ciência minimizariam a subjetividade e as tendências pessoais.

Estas premissas estão associadas a um tipo de abordagem à geração de conhecimento que enfatiza a racionalidade (ausência de contradições), a impessoalidade (quanto mais objetivo, melhor), e a predição e controle dos eventos e fenômenos estudados. Elas vão, como aponta Nielsen (1990), da descoberta de regularidades à sua predição e controle.

As pesquisas de gênero, ao contrário, são vistas, como assinala Reinharz (1983), como presas ao contexto, ligadas muitas vezes à experiência e ao envolvimento pessoal do pesquisador. São relevantes do ponto de vista social, envolvem múltiplas metodologias, não são necessariamente replicáveis e incluem emoções e eventos como experimentados pelos participantes da pesquisa.

Em parte, essas mudanças metodológicas não são específicas da área de gênero, mas, antes, estão ligadas ao fato de que, a partir da segunda metade do século $\mathrm{XX}$, começou-se a tomar consciência, no meio acadêmico, de que o método científico, como tradicionalmente entendido, não dava conta de uma de suas premissas básicas, a busca do conhecimento verdadeiro, nem do mundo físico e tampouco do mundo social, até porque a própria idéia de verdade, como entendida então, foi questionada. Na modernidade tardia, ou pós-modernidade, segundo alguns autores, para grande parte dos pesquisadores, as pretensões universalizantes associadas à filosofia ocidental se dissolveram, chegou-se à conclusão de que não há verdades absolutas a serem buscadas e o conhecimento passou a ser visto como pluralista e contextual.

Muitos fatores e teorias, ao longo do tempo, contribuíram para este cepticismo e conseqüente crise do conhecimento, que levou os pesquisadores a endossar novas abordagens ao conhecimento e à pesquisa. Entre essas teorias, podemos citar a tradição hermenêutica e a teoria crítica, também conhecida como a Escola de Frankfurt.

\section{A tradição hermenêutica e a Escola de Frankfurt}

A tradição hermenêutica, inspirada nos trabalhos de Max Weber, está preocupada com a importância do significado na interação social e, assim, acredita que, a fim de se explicar e compreender qualquer comportamento social humano não basta simplesmente observar a ação humana, mas é necessário também que se conheçam os significados atribuídos a ela pelos seus participantes. 
Apesar disso, eles ainda endossavam a distinção tradicional entre conhecimento subjetivo e objetivo, isto é, a despeito de acreditarem que a objetividade verdadeira é impossível, para eles, os cientistas sociais deveriam se abster de juízos de valor. A pesquisa na área de gênero, como veremos adiante, tem uma dimensão interpretativa, mas, diferentemente da tradição hermenêutica, ela tenta transcender ou ir além dessas preocupações com os pré-julgamentos pessoais.

A Escola de Frankfurt preocupa-se em detectar, expor e desvelar alguns aspectos da sociedade, especialmente as ideologias nela contidas, que mantém o status quo ao restringir ou limitar o acesso de diferentes grupos aos meios de se obter conhecimento. Seus integrantes rejeitam a idéia positivista de que possa existir um conhecimento "objetivo", neutro, ou uma perspectiva desinteressada, uma vez que todo pesquisador tem uma inserção histórica e social e, deste modo, esta sua inserção vai influenciar o conhecimento que é por ele produzido. Em última análise, todo conhecimento é socialmente construído.

Esta idéia, de que todo conhecimento é socialmente construído e de que não há uma perspectiva neutra para se chegar a uma verdade objetiva, está presente na maioria dos estudos de gênero. Para os pesquisadores desta área não há verdades absolutas a serem alcançadas, o conhecimento é contextual e pluralista e o essencialismo, em especial, o biológico, é questionado. Isto é, a desigualdade entre homens e mulheres não tem uma origem biológica, mas, antes, é decorrente de fatores sócio-culturais.

Os Estudos de Gênero transformaram-se, nas últimas décadas em uma das áreas centrais das ciências humanas e sociais. Como resultado das lutas feministas dos anos de 1960, as mulheres saíram da obscuridade nos estudos históricos e passaram a ser levadas em conta na pesquisa social e psicológica e na análise cultural. Ainda, em grande parte, por influência do feminismo, a “masculinidade” também foi problematizada e trazida à tona nos estudos nas áreas humanas e sociais. O gênero, assim, passou a ser considerado ponto central na análise das estruturas de poder, organização das instituições sociais e formas de controle ideológico nas sociedades modernas.

E, se o gênero é um elemento chave da ordem social e institucional, ele é também uma dimensão crucial da identidade individual. As desigualdades de gênero e as distinções entre feminilidade e masculinidade são tão profundas e marcantes sobre os sujeitos que, certamente, a categoria gênero não pode ser deixada de lado em qualquer estudo psicológico sério. E é com essa questão em mente que concluo agora falando da importância da narrativa oral e da análise de discurso para os Estudos de Gênero nas ciências humanas e sociais, de modo geral, e na Psicologia, em particular, focando mais especificamente as pesquisas que se voltam para a questão da identidade.

\section{Narrativa Oral, Identidade e Estudos de Gênero}

É dentro desta nova tradição em ciência, que alguns autores denominam pós-empírica ${ }^{6}$, que questiona a objetivida- de do conhecimento e a impessoalidade do pesquisador e que toma como importante a dimensão interpretativa da realidade social, que estão incluídos os estudos de gênero, em especial para nossos objetivos aqui, aqueles que trabalham com a narrativa oral, quer sob a forma de histórias de vida, quer sob a forma de entrevistas abertas como as que vimos utilizando em nossos trabalhos.

A narrativa oral tem sido um instrumento básico nos esforços dos trabalhos sobre gênero para incorporar vidas, atividades e sentimentos, inicialmente das mulheres e, posteriormente, também dos homens, em nossa compreensão do passado e do presente, e que não têm sido contemplados nos estudos tradicionais. A narrativa oral, como tenho afirmado reiteradas vezes, se apresenta como uma das melhores formas de se fazer com que as pessoas falem sobre suas vidas, porque permite ao pesquisador explorar não apenas fatos e atividades como também sentimentos, isto é, a experiência emocional de seus informantes. Ao falar, as pessoas constroem identidades, articulam suas experiências e refletem sobre o significado destas experiências para si (ver, a esse respeito: Bruner, 1987, 1990; Chafe, 1990; Kerby, 1991; Linde, 1993; Schiffrin, 1996; entre outros). Deste modo, através de suas narrativas podemos obter um quadro mais amplo de como os entrevistados se percebem no mundo, de como e a quê atribuem valor, e do significado particular atribuído a suas ações e a seu lugar no mundo.

Neste sentido, a narrativa oral tem se mostrado especialmente importante nos estudos de gênero. No caso das mulheres, ao dar voz a elas, torna-se possível que se dê conta da natureza dialética de sua consciência - como é o caso, por exemplo, da percepção de que o trabalho de casa é considerado trabalho e não trabalho. Os meios de se conhecer e falar sobre as mulheres e seus mundos foram, durante muito tempo, descritos por homens, que vêm ocupando uma posição especial na sociedade. Assim, torna-se importante que as mulheres falem sobre suas experiências, sobre sua situação no mundo, a fim de que assumam a autoria sobre suas vozes e vidas. Além disso, num mundo estruturado basicamente por homens, a habilidade das mulheres de valorizar seu próprio pensamento e sua experiência é, muitas vezes, bloqueada por dúvidas e hesitações quando sua experiência pessoal não está de acordo com os mitos e valores que dizem respeito a como uma mulher “deve” ser, se comportar e sentir, isto é, com a identidade que para elas foi construída.

Uma análise mais atenta da linguagem e dos significados de palavras importantes por elas utilizadas para descrever sua experiência nos permite melhor compreender como as mulheres estão vendo e se adaptando à cultura na qual vivem. Isto porque, como assinalam Anderson, Armitage, Jack e Wittner (1990), a situação das mulheres é, de certo modo, especial: de um lado, com freqüência, elas têm, pelo menos aparentemente, aceitado os estereótipos que as definem como dependentes, passivas, voltadas para os outros e gentis e, de outro, estes traços são valorizados negativamente na sociedade mais ampla e é quase impossível viver segundo eles. Assim, ao contrário do que ocorre com os homens, os con- 
ceitos que dão forma às experiências pessoais das mulheres usualmente diminuem as mulheres e são, desta forma, muitas vezes, ao mesmo tempo, valorizados e desvalorizados em suas falas, numa tentativa de rejeitar e tentar se enquadrar no que é socialmente esperado e aceito. O padrão que, em suas mentes, elas continuamente repelem e, ao mesmo tempo, almejam alcançar é uma imagem generalizada de como as mulheres devem pensar e sentir, imagem essa reforçada pela cultura mais ampla em que estão inseridas e pelas pessoas à sua volta, inclusive suas próprias famílias.

A partir das questões levantadas acima, não nos parece suficiente saber, muitas vezes, através de uma análise do conteúdo, quais temas dominam uma narrativa oral. Como observa Nancy Cott (1978),

The meaning which women ascribe to their own behavior is reducible neither to the behavior itself nor to the dominant ideology. It is derived from women's consciousness which is influenced by the ideas and values of men. But is nevertheless uniquely situated, reflective of women's concrete position within the patriarchal power structure. (p. 103)

É preciso, assim, ir além, explorando também a forma mesma de seus discursos e o significado das palavras empregadas $^{7}$, se quisermos melhor dar conta desta duplicidade da mente de nossas entrevistadas mulheres ${ }^{8}$.

Essa duplicidade, apesar de se fazer mais forte no caso das mulheres, nos parece algo típico do sujeito contemporâneo em que as identidades estáveis do passado tornaram-se, no momento atual de descontinuidade e fragmentação, uma “celebração móvel”, para utilizar a expressão empregada por Hall (1997), ou seja, são continuamente formadas e transformadas em relação às formas pelas quais os sujeitos têm sido representados nos sistemas culturais que os rodeiam. Assim, do mesmo modo que as mulheres, os homens de hoje também parecem oscilar entre atitudes supostamente mais "modernas”, relacionadas aos novos papéis e posições deles esperados e por eles ocupados na sociedade, e mais "tradicionais”, isto é, vinculadas à antiga identidade masculina.

Contudo, diferentemente das mulheres, mais especialmente as de classe média, para quem os novos modelos foram fruto de uma insatisfação pessoal e de uma árdua batalha levada adiante para que fossem socialmente aceitos, o novo modelo masculino foi, em grande parte, fruto não de uma insatisfação pessoal, mas desencadeado pelas alterações no papel e na posição das mulheres na sociedade. Além disso, enquanto, para essas mulheres, “alcançar a outra margem" e abordar o terreno masculino do trabalho e da profissão é valorizador, para os homens, colocar-se no terreno doméstico "menor" das mulheres sempre foi considerado desvirilizante e, portanto, socialmente desvalorizado. Deste modo, muitos homens, mesmo aqueles das clas- ses médias intelectualizadas, ainda relutam em exprimir sua parte "feminina", porque temem perder sua virilidade e todas as vantagens a ela relacionadas e a que têm direito ainda no mundo atual.

Gostaria de finalizar afirmando que acredito, assim, que se quisermos melhor entender como as ideologias dominantes, muitas vezes contraditórias, refletidas e reforçadas pelos diferentes tipos de discurso, estruturam nossas instituições e moldam a vida cotidiana das pessoas, é necessário ouvir não apenas o que as pessoas reais dizem de suas vidas concretas, mas também como elas o dizem e porque o fazem desta forma. Como assinala Schiffrin (1996), "the form, content, and performance of narrative all provide sensitive indices of our personal selves and our social and cultural identities" (p. 194). É nesse sentido, portanto, que acredito que o uso de narrativas orais e da análise de discurso pode ser um rico e poderoso instrumento para uma melhor compreensão de mulheres e homens e em muito pode contribuir para os Estudos de Gênero nas ciências humanas e sociais, em geral, e na Psicologia, em particular.

\section{Referências}

Anderson, K., Armitage, S., Jack, D., \& Wittner, J. (1990). Beginning where we are: feminist methodology in oral history. In J. M. Nielsen (Org.), Feminist research methods. Exemplary readings in the Social Sciences. Boulder, Colorado: Westview.

Bruner, J. (1987). Life as narrative. Social Research, 54, 11-32.

Bruner, J. (1990). Acts of meaning. Cambridge, Massachusetts: Harvard University Press.

Chafe, W. (1990). Some things that narratives tell us about the mind. In B. Britton \& A. D. Pellegrini (Orgs.), Narrative thought and narrative language. Hillsdale, New Jersey: Erlbaum.

Cott, N. (1978). Passionlessness: the interpretation of Victorian sexual ideology, 1790-1850. Signs, 4, 219-236.

Hall, S. (1997). Identidades culturais na pós-modernidade. (T. S. Tomas \& L. L. Guacira, Trad.). Rio de Janeiro: DP\&A.

Kerby, A. P. (1991). Narrative and the self. Bloomington, Indiana: Indiana University Press.

Lakoff, R. (1975). Language and woman's place. Nova York: Harper Colophon. Linde, C. (1993). Life stories. Oxford: Oxford University Press.

Nielsen, J. M. (1990). Introduction. In J. M. Nielsen (Org.), Feminist research methods. Exemplary readings in the Social Sciences. Boulder, Colorado: Westview.

Reinharz, S. (1983). Experiential analysis: a contribution to feminist research. In G. Bowles \& R. D. Klein (Orgs.), Theories of Women's Studies. Londres: Routledge \& Kegan Paul.

Rocha-Coutinho, M. L. (1998). A análise do discurso em psicologia: algumas questões, problemas e limites. In L. Souza, M. F. Quintal de Freitas, \& M. M. P. Rodrigues (Orgs.), Psicologia: reflexões (im)pertinentes. São Paulo: Casa do Psicólogo.

Schiffrin, D. (1996). Narrative as self-portrait: sociolinguistic constructions of identity. Language and Society, 25, 167-203. 
${ }^{1}$ A fim de que o leitor possa melhor entender o ponto central deste artigo - a importância do uso da narrativa oral e da análise de discurso nas pesquisas na área de relações de gênero -, inicio meu texto discorrendo, de forma breve, sobre a metodologia científica, apontando, em especial, as contribuições dos estudos feministas para as metodologias tradicionalmente empregadas nos estudos acadêmicos.

${ }^{2}$ Robin Lakoff, renomada professora do Departamento de Lingüística da University of Califórnia, Berkeley, agitou muito o campus no início da década de 1970, especialmente as mulheres, levantou polêmica, ao escrever uma série de artigos sobre mulher, discurso e sociedade para o jornalzinho da universidade e acabou por publicar, em 1975, o livro Language and Woman's Place, que caiu como uma "bomba" nos meios acadêmicos mais tradicionais, suscitando uma série de críticas, especialmente do ponto de vista metodológico, por não atender a uma série de preceitos fundamentais do que se acreditava ser uma metodologia científica. De qualquer modo, os trabalhos de Lakoff constituíram um marco nos Estudos de Gênero na Universidade de Berkeley (na época, Women's Studies) e tiveram influência na criação desses Centros de Estudo sobre a Mulher em outras universidades estadunidenses.

${ }^{3}$ Cabe aqui uma observação. É meu ponto de vista que as metodologias quantitativas não se opõem às qualitativas mas, antes, as complementam; elas suprem as limitações umas das outras.

${ }^{4} \mathrm{E}$ aqui cabe um aparte. Em mesa redonda sobre identidade de gênero de que participei apresentando estudo em que entrevistei e analisei os discursos de estudantes universitários dos sexos feminino e masculino, fiquei impressionada com o fato de minhas conclusões serem muito próximas às do trabalho apresentado pela professora Maria Cristina Ferreira, que submeteu estudantes universitários de ambos os sexos a um questionário fechado e fez uso de metodologia quantitativa para analisar os dados.

${ }^{5}$ Durante o meu curso de Mestrado nos Estados Unidos tive uma disciplina, Observação do Comportamento Infantil, cujo objetivo era treinar os alunos para que se tornassem observadores o mais neutros, isentos e objetivos possível.

${ }^{6}$ Estamos aqui chamando de pós-empírico a um momento de mudança - na filosofia da ciência, epistemologia, sociologia do conhecimento e áreas correlatas -, que se caracteriza pelo desenvolvimento de metodologias alternativas aos métodos científicos tradicionais para o estudo do mundo social.

${ }^{7}$ Para uma discussão acerca do uso e da importância da análise do discurso em psicologia, de modo geral, ver Rocha-Coutinho, 1998.

${ }^{8}$ Mulheres entrevistadas, por exemplo, ao contar sobre sua separação, em que haviam, de uma forma ou de outra, “expulsado" seus maridos de casa (mandando ele sair ou, até mesmo, pondo as coisas dele do lado de fora de casa e trocando a fechadura), começaram sua narrativa dizendo "Meu marido me abandonou ...”. Em que pese o possível e provável "abandono” de seus maridos ao longo da vida em comum, acreditamos que esta contradição aparente em seus discursos e sua importância para uma melhor compreensão das mulheres e da "duplicidade” de suas mentes, só pode ser, a nosso ver, trabalhada por uma análise que leve em conta não apenas o conteúdo do que foi dito, mas também a forma e a função de seus discursos.

Maria Lúcia Rocha-Coutinho, doutora em Psicologia Clínica pela Pontifícia Universidade Católica do Rio de Janeiro, é professora adjunta no Instituto de Psicologia, Universidade Federal do Rio de Janeiro. Endereço para correspondência: Rua Engenheiro Cortes Sigaud, 187 apt. 401; Leblon; Rio de Janeiro, RJ; CEP 22450 150. Tel: (21) 2294-9452. Fax: (21) 2294-0338. E-mail: mlrochac@imagelink.com.br 